\title{
Who should bear the risk of the removal of the non-conforming goods?
}

\author{
Joined cases C-65/09 and C-87/09 (Weber and Putz)
}

\author{
Joasia Luzak
}

(C) Springer-Verlag 2012

\section{Introduction}

Article 3 Consumer Sales Directive ${ }^{1}$ establishes the system of liability of the seller for the non-conformity of goods, delivered by him to the consumer. On the basis of this provision, the consumer is entitled to have the goods brought into conformity either by way of repair or replacement of the defective goods. Regardless of the remedy chosen by the consumer, the seller has to provide that remedy free of charge and without significant inconvenience to the consumer. The European legislator has, however, taken into account that providing a certain remedy might cause the seller undue hardship. Therefore, the seller is released from having to provide a remedy chosen by the consumer if this would be impossible or disproportionate. Since the Consumer Sales Directive introduced a hierarchy of remedies, the consumer may demand price reduction or terminate the contract only in case he is not entitled either to repair or to replacement.

Since the publication of this Consumer Sales Directive, there have been many problems with the interpretation of Art 3. For example, adoption of the system of hierarchy of remedies has been a controversial idea. ${ }^{2}$ It has also been

\footnotetext{
${ }^{1}$ Directive 1999/44/EC of the European Parliament and of the Council of 25.05.1999 on certain aspects of the sale of consumer goods and associated guarantees, OJ 1999 L 171/12.

${ }^{2}$ On hierarchy of remedies in the Sales Directive see: Staudenmeyer, The Directive on the Sale of Consumer Goods and Associated Gua-
}

Assistant Professor at the Centre for the Study of European Contract Law, University of Amsterdam.

Asst. Prof. Dr. Joasia Luzak $(\bowtie)$

Afdeling Privaatrecht A, Oudemanhuispoort 4-6,

1012 CN Amsterdam, The Netherlands

e-mail: <J.A.Luzak@uva.nl> questioned why the Consumer Sales Directive does not clearly specify when the risk for the defective goods passes from the seller to the consumer, leaving a certain gap that needed to be filled by national laws and interpretation norms. ${ }^{3}$ However, only recently another issue became the subject of the judicial debate: who should bear the risk of the removal of the non-conforming goods and of the re-installation of the new, conforming goods? This was the main question considered by the Court of Justice of the European Union in two recent joined cases: Weber and Putz. ${ }^{4}$

\section{Facts}

In the case of Weber/Wittmer, Mr Wittmer bought polished Italian-manufactured floor tiles at a price of $€ 1.382,27$ from Gebr. Weber GmbH. The consumer laid the floor tiles in his house by himself, with no help from the seller. Subsequently, shading appeared on the surface of the tiles, visible to the naked eye. It was clear that the installation did not damage the tiles and that in this case the delivered goods had already not been in conformity with the contract at the moment of delivery. It was also established that the marks on the tiles could not be removed, so that out of the two pri-

rantees - A Milestone in the European Consumer and Private Law, ERPL 2000, 554-556; Hondius/Jeloschek, Towards a European Sales Law - Legal Challenges posed by the Directive on the Sale of Consumer Goods and Associated Guarantees, ERPL 2001, 159-160; Micklitz, Sale of consumer goods, in Micklitz/Reich/Rott, Understanding EU Consumer Law (2009) 167-171; Magnus, Consumer sales and associated guarantees, in Twigg-Flesner, European Union Private Law (2010) 251-254.

${ }^{3}$ On the passing of risk in the Sales Directive see: Staudenmeyer, ERPL 2000, 553-554; Micklitz in Understanding EU Consumer Law 163.

${ }^{4}$ CJEU 16.06.2011 joined cases C-65/09 (Weber) and C-87/09 (Putz). 
mary remedies available to consumers under the Consumer Sales Directive only replacement of the tiles was possible. The costs for the replacement of the floor tiles were estimated by the expert at $€ 5.830,57$. These high costs included the costs for removal of the old, faulty tiles, as well as the costs of the delivery and installation of new floor tiles of the same type, which were free of fault.

In the case Putz/Medianess Ms Putz purchased a dishwasher from Medianess which the company had delivered to the door of her house. After Ms Putz had the dishwasher installed, a defect became apparent, which was not attributable to the installation but to the machine itself. Again, it was established that the repair of the defect was not possible. As a result, Ms Putz requested not only the delivery of a new dishwasher, free from defects, but she also argued that she had a right to claim from the seller the disconnection and the removal of the defective machine in her kitchen and the installation of the new one without extra charge.

In both cases it was clear that the delivered goods were not in conformity with the contract and that the consumer had a right to claim one of the remedies available to him under the regime of Art 3 Consumer Sales Directive. Of primary remedies, only replacement was possible. Unfortunately, if the consumer chose for replacement of the non-conforming goods, such a choice brought with it extra costs, i.e. of removing the defective, old goods and re-installing the new goods. In both cases the same question was raised: may a consumer demand from the seller that he covers these extra costs? ${ }^{5}$

Additionally, the Weber case also addressed another issue. The German court asked the CJEU whether the seller is obliged to bear disproportionate costs for one of the remedies that the consumer may choose, if the other primary remedy is impossible. ${ }^{6}$ This question suggests that even if the answer to the previous question was affirmative, i.e. the seller would be seen as a party responsible for covering the extra costs of the removal of the defective goods and of the re-installation of the new goods, then there might still be a defence available to the seller to refuse to perform this particular remedy based on its disproportionate nature.

\section{Who pays for the removal of the non-conforming goods after they have been installed?}

As the two cases discussed here show, the consumers' problems with receiving non-conforming goods do not end if and when the seller agrees to fulfil his obligation to remedy

\footnotetext{
${ }^{5}$ Para 23 and 32 (Weber and Putz).

${ }^{6}$ Para 23 (Weber and Putz)
}

the non-conformity. Even if the seller agrees to replace or repair the non-conforming goods, the consumer often has to bear extra costs as a result of that non-conformity. For example, when the consumer chooses to purchase a particular good, he takes into account how much it will cost him (in money or, if he installs it himself, in time) to have that good installed in his house and makes his transactional decision - i.e. whether to buy that good - on the basis of the total cost estimation. However, no one who buys a good calculates in its total price the possibility that this good will end up being non-conform and that it will have to be removed and replaced by another, conforming good. If it is then expected from the consumer to cover these extra charges, then he will end up paying double the service amount that he intended to, and had taken into account in his calculations.

On the other hand, the seller, who is often not responsible for the non-conformity of the goods, does not have a contractual obligation to install these goods at the consumer's place (unless the parties agree to that effect). When the seller concludes a transaction with a consumer he assumes an obligation to deliver to a consumer a good and therefore he calculates in his business expenses only the extra charge for delivery, at the most. If it is expected from the seller to cover the extra charges of removing the non-conforming goods and re-installing the new, conforming goods, it would then be the seller who would have to face additional expenses.

The CJEU was asked to interpret Art 3 Consumer Sales Directive to answer whether it prescribed who should bear the risk of the removal of the non-conforming goods after they had been installed by the consumer, and the costs for the re-installation of the new, conforming goods.

\section{Advocate General's opinion: the consumer}

Advocate General Mazák when he was considering who should bear the risk (and the costs) of the removal of the non-conforming goods and of the re-installation of the new, conforming goods, focused on the fact that the goods were originally meant to be installed by the consumer. Pursuant to the Advocate General, the seller was not obliged under the contract of sale to pay or arrange for the installation of the goods, and therefore the consumer could not expect the seller to arrange for it in case of non-conformity of the goods. ${ }^{7}$ The Advocate General implies therefore that the rights of the consumer to demand subsequent performance from the seller are limited by the scope of the obligations that were originally contracted under the contract of sale. ${ }^{8}$ To arrive at this conclusion the AG uses mainly a contextual and sys-

\footnotetext{
${ }^{7}$ Para 68 (opinion Putz) 18.05.2010 C 87/09, Para 49 (opinion Weber) 18.05.2010 C-65/09; the opinions of the AG were given separately.

${ }^{8}$ Para 46-55 (opinion Putz), Para 45-54 (opinion Weber).
} 
tematic interpretation of Art 3 Consumer Sales Directive, which allows him to interpret this provision as obliging the seller only to bring the consumer into possession of goods free of defect. ${ }^{9}$ What the consumer would then do with the conforming goods that are in his possession, is, according to the $\mathrm{AG}$, up to his own discretion.

One of the reasons why the AG thinks that it should be the consumer who pays for the removal of the non-conforming goods and the re-installation of the new, conforming goods, is the fact that the seller has no influence on how the consumer decides to use the product after he has purchased it. ${ }^{10}$ Therefore, if it were the seller who would need to bear these costs, the scope of his liability would be unpredictable. The seller would be dependent on the circumstances occurring after the risk for the goods had passed to the consumer. Depending on what the consumer would decide to do with the purchased goods, the costs of removing them and re-installing the new, conforming goods could vary drastically. ${ }^{11}$ Consumer's choice is, of course, limited by an obligation to use the goods in accordance with the nature of the product, but it still leaves a lot of options available to him.

The last argument that the AG has made concerned the interpretation of the wording of Art 3, in particular its phrase that the goods need to be brought into conformity "free of charge" and "without insignificant inconvenience" to the consumer. ${ }^{12}$ According to the AG these phrases could not be interpreted as obliging the seller to remove the nonconforming goods and to re-install the new, conforming goods at his own expense. The AG believes that these phrases were supposed to apply only to the method of how to bring the non-conforming goods back into conformity and that they do not prescribe any material obligations for the seller.

Upon reading the arguments presented by the $\mathrm{AG}$ it does not come as a surprise that the AG concluded that if the consumer claims replacement of the non-conforming goods, he may expect only a delivery of the new, free of faults goods from the seller. Of course, there is still a possibility that the consumer could claim other costs under the national laws of the Member States, but the Consumer Sales Directive does not give the consumer any other rights, according to the $\mathrm{AG} .{ }^{13}$

\section{CJEU's judgment: the seller}

The CJEU focused on the last argument put forward by the $A G$ in answering the question posed by the German Supreme

\footnotetext{
${ }^{9}$ Para 55 (opinion Putz), Para 54 (opinion Weber).

${ }^{10}$ Para 57 (opinion Putz), Para 56 (opinion Weber).

${ }^{11}$ Para 64 (opinion Putz), Para 63 (opinion Weber).

${ }^{12}$ Para 66 (opinion Putz), Para 65 (opinion Weber).

${ }^{13}$ Para 59 (opinion Putz), Para 58 (opinion Weber).
}

Court (BGH). Surprisingly, the CJEU's position was drastically different than that of the Advocate General. Namely, it was the seller who was seen by the CJEU as having to bear the responsibility for the costs of the removal of the defective goods and of the re-installation of the new, conforming goods. ${ }^{14}$ This is an interesting position since it may lead to the situation that when a consumer buys, e.g., a bookshelf at IKEA, installs it himself at home but the bookshelf turns out to be non-conform, IKEA would be obliged to remove the faulty bookshelf from the consumer's home, as well as deliver and install a new, conforming bookshelf.

The CJEU clearly interprets the wording of Art 3, i.e. obligation of the seller to bring goods into conformity "free of charge", as an essential element of consumer protection, intended to protect consumers from the risk of financial burdens which could dissuade them from using their rights. ${ }^{15}$ This does not come as a surprise since the same argument was raised previously in the CJEU case Quelle. ${ }^{16}$ If the consumer were made to pay for the removal of the defective goods and for the re-installation of the new, conforming goods, it would clearly create such an additional financial burden for the consumer. ${ }^{17}$ As a result, the consumer would not be able to exercise his rights given to him in Art 3 Consumer Sales Directive, without having to bear this additional financial burden. ${ }^{18}$ This cannot be seen any differently than as being contrary to the "free of charge" principle of Art 3. ${ }^{19}$ It has been argued in this case that the charges that the consumer does not have to pay that are listed in the Consumer Sales Directive do not mention the cost of the removal of the defective goods etc. but, as it has already been stated by the CJEU in the Quelle case, ${ }^{20}$ the list in the Consumer Sales Directive may not be seen as exhaustive. ${ }^{21}$ The costs of removing the defective goods and of reinstalling the new, conforming goods are seen as necessary costs of the replacement, i.e. costs that need to be incurred to bring the goods into conformity. ${ }^{22}$ Moreover, the CJEU notices that the consumer would clearly experience "significant inconvenience" if the seller agreed to replace the defective goods, but would not have removed the defective goods nor re-installed the new goods. ${ }^{23}$

These arguments are the main ones used by the CJEU to conclude that the seller should pay the cost of the removal

\footnotetext{
${ }^{14}$ Para 62 (Weber and Putz).

${ }^{15}$ Para 45 and 46 (Weber and Putz).

${ }^{16}$ CJEU 17.04.2008 case C-404/06 (Quelle) Para 34.

${ }^{17}$ Para 47 (Weber and Putz).

${ }^{18}$ Para 48 (Weber and Putz).

${ }^{19}$ Para 49 (Weber and Putz).

${ }^{20}$ CJEU 17.04.2008 case C-404/06 (Quelle) Para 31.

${ }^{21}$ Para 50 (Weber and Putz).

${ }^{22}$ Para 50 (Weber and Putz).

${ }^{23}$ Para 53 (Weber and Putz).
} 
of the defective goods and the cost of the re-installation of the new, conforming goods. It is important to mention that the CJEU clearly rejected the AG's idea that the scope of the liability of the seller should correspond to the scope of his original contractual obligations. ${ }^{24}$ The CJEU stated that based on the contractual obligations non-conformity of the goods may be determined. However, after the non-conformity has been established additional obligations arise for the parties, based on Art 3 Consumer Sales Directive and other provisions in the national laws of the Member States. These obligations are independent of the contractual obligations agreed upon by the parties themselves.

The CJEU does not address the other concern that the AG expressed, namely the extension of the seller's liability to cover situations that would happen after the risk had already passed from the seller to the consumer. Instead the court focuses on making it clear that the conclusion reached by it was a fair outcome. To that purpose it reminded a previous statement of the CJEU in the case Quelle ${ }^{25}$ listing a failure on a part of the seller to correctly perform his contractual obligations as a reason to place more risk on him rather than on a consumer. ${ }^{26}$ Since the additional costs that need to be made by one of the parties would have been avoided if the seller had correctly performed his original contractual obligations, it is an equitable outcome, according to the CJEU, to oblige the seller to cover these costs. ${ }^{27}$ Additionally, the judges of the CJEU correctly notice that if this burden is placed on the seller, then the seller may also count on sufficient legal protection of his financial interests, e.g. he may use the right of redress against a person who is responsible for the non-conformity (Art 4 Consumer Sales Directive), or he has the right to refuse performing a disproportionate remedy (Art 3 Consumer Sales Directive), or he may be reassured that claims would not be brought against him after the lapse of the 2 year limit set in Art 5 Para 1 Consumer Sales Directive.

Taking all these arguments into consideration the CJEU decided that in case a consumer claims replacement of the defective goods, then the seller is liable for costs involved with the removal of these defective goods, as well as the costs of the re-installation of the new, conforming goods. It is, of course, left to the national courts to determine what necessary costs there are in a specific case, for which the consumer may claim reimbursement from the seller. ${ }^{28}$

\footnotetext{
${ }^{24}$ Para 59 (Weber and Putz).

${ }^{25}$ CJEU 17.04.2008, case C-404/06 (Quelle), Para 41.

${ }^{26}$ Para 56 (Weber and Putz).

${ }^{27}$ Para 57 (Weber and Putz).

${ }^{28}$ Para 61 (Weber and Putz).
}

\section{Disproportionate remedies}

As mentioned previously, in the Weber case another question was raised with which the German court tried to clarify the hierarchy of remedies that the Consumer Sales Directive contains. Article 3 specifies that a consumer may claim one of the two primary remedies from the seller, i.e. repair or replacement, and the seller is obliged to remedy the goods in the way chosen by the consumer, unless the remedy chosen is either impossible or disproportionate. In the analyzed cases, the repair of the goods was impossible, which left replacement as the only primary remedy that the consumer could claim. However, taking into account the additional costs for the removal of the defective goods and the re-installation of the new, conforming goods which, as the CJEU established, were the responsibility of the seller to bear, the replacement brought about with it lots of additional expenses, far exceeding the original sales price. In the Weber case the question was raised whether the seller may refuse to replace the defective goods claiming that performance of this remedy causes him disproportionate expenses.

The Advocate General argued in his opinion that the seller indeed has a right to refuse performance of a primary remedy if it is disproportionate, even if the other primary remedy is already impossible. According to the AG, the consumer may in such a situation freely claim one of the secondary remedies, i.e. price reduction or contract termination. ${ }^{29}$ The AG considered this to be the only reasonable interpretation of Art 3, since if the consumer could claim a primary remedy even if it was disproportionate, the use of secondary remedies mentioned in this Article would be seriously limited. The secondary remedy could only be claimed by a consumer when both primary remedies would be impossible. ${ }^{30}$ Interestingly, the AG admits himself that even though he chooses this interpretation of Art 3, it does not follow directly from the precise wording of this provision. ${ }^{31}$ Article 3 Para 3 states that the test to determine whether the remedy is proportionate should be conducted by reference to 'the alternative remedy'. This clearly suggests that the requirement of proportionality applies only to a situation in which the consumer chooses between the two primary remedies and not between one of the primary remedies and secondary remedies, e.g. the seller should not be able to refuse to repair the defective goods just because it would cost him less money to terminate the contract with the consumer. Still, the AG chooses not to follow the literal meaning of this Art 3 Para 3 since such a literal interpretation would lead to an unduly disregard for the seller's inter-

\footnotetext{
${ }^{29}$ Para 81 (opinion Weber).

${ }^{30}$ Para 84 (opinion Weber).

${ }^{31}$ Para 82 (opinion Weber).
} 
ests and would distort a fair balance between the interests of both parties. ${ }^{32}$

The CJEU while considering this question focused on the wording of Art 3 Para 3 of the Consumer Sales Directive. According to the CJEU this provision has to be interpreted as setting the test of a relative, and not absolute, lack of proportionality. ${ }^{33}$ This means that whether a primary remedy may be seen as disproportionate can be ascertained only in comparison with the other alternative, primary remedy. It is not possible for the seller to make a general estimation that the costs of a primary remedy are too high in comparison to the original sales price and on that ground to refuse to perform this remedy. This finding may also be based on Recital 11 Consumer Sales Directive which states that a remedy is disproportionate if it imposes, in comparison with the other remedy, unreasonable cost. ${ }^{34}$ In order to determine whether the costs are unreasonable, the cost of the one primary remedy should be significantly higher than the costs of the other primary remedy. A specific test is therefore set for determining whether the remedy is disproportionate and there is no room left for an abstract assessment. This leads the CJEU to a conclusion that as long as only one primary remedy is available, the seller may no longer refuse it. ${ }^{35}$ The reason for this is that this remedy could never be declared as disproportionate since the other remedy is impossible and its cost is undeterminable.

Although the CJEU chooses to follow the literal interpretation of Art 3 Consumer Sales Directive, it clearly shares the concerns of the AG as to the heavy burden that this interpretation may place on the seller. Therefore, the CJEU states that the consumer's right to claim a remedy from the seller could be limited to the payment of only a "proportionate" amount by national courts. ${ }^{36}$ Until this part of this judgment the CJEU clearly put the interests of the consumers over the interests of the sellers and ruled in a way that would lead to increasing consumer protection, mostly by giving consumers more legal certainty. However, by introducing an exception from the above-described clear rules, the CJEU blurred the expected positive effects of this judgment. It is unclear what exactly the national courts will see as a "proportionate" amount that consumers may claim from the sellers as a remedy. The CJEU states that while calculating this amount the national court should consider the value of the goods without non-conformity, the significance of the non-conformity as well as the Consumer Sales Directive's purpose, which is ascertaining a high level of consu-

\footnotetext{
32 Para 85 (opinion Weber).

${ }^{33}$ Para 68 (Weber and Putz).

${ }^{34}$ Para 69 (Weber and Putz).

${ }^{35}$ Para 71 (Weber and Putz).

${ }^{36}$ Para 74 (Weber and Putz).
}

mer protection. ${ }^{37}$ This last element means that the reduction of the reimbursement for which the consumer asks may not render the right to replacement ineffective. ${ }^{38}$

It is worth mentioning that it is unclear what exactly the introduction of this rule will mean for consumers in practice. In the Weber case, the consumer claimed the replacement of the floor tiles. The seller was asked to pay for the removal of the defective floor tiles, new tiles and their installation. The cost of the removal of the defective floor tiles and of the re-installation of the new floor tiles was higher than the cost of the new floor tiles. What could the consumer expect to have reimbursed in such a case? According to the first answer given by the CJEU, he could expect for the seller to bear all these costs. However, the second answer allows for the seller to demand limitation of this reimbursement from the national court. If the national court considered as a proportionate cost only the value of the new tiles, that in practice would overturn the verdict of the CJEU given in reply to the first question that was posed by the BGH, since it would be the consumer who would end up bearing the costs of the removal of the defective goods and of the reinstallation of the new, conforming goods. It will remain to be seen what the national courts would consider as a "proportionate" amount.

This leaves consumers in an uncertain position since they may not be willing to wait until the judgment is given with bringing the goods into conformity. If they decide to claim the primary remedy and the seller refuses to cover all the costs involved therewith, the consumer could choose to have the goods brought into conformity by a third party and then to claim the costs thereof from the seller. However, if the consumer cannot be certain whether he will receive reimbursement for all the costs that he would have needed to make from the seller, he may want to choose a price reduction or terminate the contract instead. Pursuant to the Consumer Sales Directive, a consumer may choose a secondary remedy if the primary remedy may not be performed without a significant inconvenience to the consumer. The reduction of the reimbursement can be seen as creating such a significant inconvenience to the consumer, ${ }^{39}$ which enables the consumer to choose for a secondary remedy. However, by the time that the judge decides to reduce the reimbursement's amount, the consumer is likely to have already chosen a certain primary remedy and have encumbered all additional costs thereof, which means he would rather have these costs fully reimbursed than terminate the contract or ask for price reduction. If the consumer knew from the start that his claim for reimbursement would be reduced he might take that into account when choosing a

\footnotetext{
${ }^{37}$ Para 76 (Weber and Putz).

${ }^{38}$ Para 76 (Weber and Putz).

${ }^{39}$ Para 77 (Weber and Putz).
} 
remedy, but the fact that the reduction remains discretionary leads to legal uncertainty. In practice, the consumer is left with not knowing what he should do to be better off in case the goods delivered to him and installed by him are defective. Similarly, the seller does not know to what extent his obligations go and therefore what he has to offer to the consumer. The CJEU's decision therefore leaves both parties in the dark as to their rights and obligations.

\section{Conclusion}

This judgment came as a surprise to most. Upon analyzing the judgment it is clear that while the CJEU interpreted Art 3 Consumer Sales Directive in a consumer-friendly way and gave a clear rule strengthening consumer protection in an answer to the first question that was discussed here, the answer to the second question took away much of that original effect. Arguably, the answer to the second question restores the balance between the interests of the consumers and the sellers, but it will also lead to legal uncertainty for both consumers and sellers, neither of who will be able to foresee what legal consequences a choice of a particular remedy will have for them.

Interestingly, in the Feasibility Study ${ }^{40}$ which is likely to become an Optional Instrument ${ }^{41}$ that the European consumers could choose to have applied to their sales contracts, there is a specific provision regulating the same matter. Pursuant to Art 113 Feasibility Study, when the seller remedies non-conformity by replacement, that seller has an obligation to take back the replaced item at the seller's expense. The creators of this provision considered that cost to be a responsibility of the seller to bear, just like the CJEU did. While this provision does not regulate who should bear the costs of the re-installation of the new, conforming goods, it still gives more legal certainty to consumers, since it is an absolute rule. There is no exception provided in the Feasibility Study to limit the costs of the removal of the defective goods, in case they are not "proportionate" ${ }^{42}$ which means that consumers will know exactly what they might expect in return from the seller if they choose to claim replacement of the defective goods. Additionally, it is clear that the Feasibility Study introduces an absolute lack of proportionality as a test to determine whether the seller may refuse performance of a costly remedy. ${ }^{43}$ This rule, again, gives consumers more legal certainty since they may be sure that whenever they ask for an expensive remedy, the seller would choose to offer the consumers a price reduction or termination of the contract instead.

In comparison to the rules introduced by the CJEU, the provisions of the Feasibility Study may seem at a first glance less consumer-friendly, but they aim at increasing consumer protection by giving consumers more legal certainty. Maybe they could be an inspiration for the European Commission when the time comes to review the provisions of the Consumer Sales Directive. However, taking into account that provisions of the Consumer Sales Directive have been removed from the last version of the harmonized Consumer Rights Directive, ${ }^{44}$ it is difficult to foresee when the next possibility to revise the Consumer Sales Directive will arise.

\footnotetext{
${ }^{40}$ A European contract law for consumers and businesses: Publication of the results of the feasibility study carried out by the Expert Group on European contract law for stakeholders' and legal practitioners' feedback, <ec.europa.eu/justice/contract/files/feasibility-study_en.pdf> (Feasibility Study); see Zoll, Das Konzept des Verbraucherschutzes in der Machbarkeitsstudie für das Optionale Instrument Rechtfertigung der Differenzierung des persönlichen Anwendungsbereiches einzelner Normen, euvr 2012, 10.1007/s13590-011-0004-4.

${ }^{41}$ See e.g. Reding, The Next Steps Towards a European Contract Law for Businesses and Consumers, Speech/11/411, keynote speech of the Commissioner Reding during the symposium 'Towards a European Contract Law', Leuven 03.06.2011, 9 <europa. $\mathrm{eu} / \mathrm{rapid} /$ pressReleasesAction.do?reference $=\mathrm{SPEECH} / 11 / 411 \&$ format $=$ HTML\&aged $=0$ \&language $=E N \&$ guiLanguage $=e n>$.
}

\footnotetext{
${ }^{42}$ Of course, general rules on acting in good faith may apply in this situation (compare Art 2, 5, 24, 49, 50, 60, 69 84, 87, and 90 Feasibility Study), but that could be said also for the national laws of the Member States, most of which have a similar provision that would apply to provisions implementing Art 3 Consumer Sales Directive.

${ }^{43}$ Article 111 Para 3 lit b Feasibility Study.

${ }^{44}$ Version of 23.06.2011 is available online: <europarl.europa.eu/ sides/getDoc.do?pubRef=-//EP//TEXT+TA+P7-TA-2011-0293+ $0+\mathrm{DOC}+\mathrm{XML}+\mathrm{V} 0 / / \mathrm{EN} \&$ language $=\mathrm{EN} \#$ top $>$.
} 